\title{
LESS IMPORTANT ROLE OF FAMILY SIZE REDUCTION IN THE RECENT DRASTIC DECREASE OF CONSANGUINEOUS MARRIAGE IN JAPAN ${ }^{1}$
}

\author{
Katumi Tanaka and Reiko Hayase \\ Department of Human Genetics, \\ Tokyo Medical and Dental University, \\ Tokyo, Japan
}

\begin{abstract}
Summary The consanguinity rate in Japan has rapidly decreased during the last 20 years. Possible causes of such decrease were analyzed by comparing chronological changes in the mean number of opposite-sex first cousins and in the rate of first-cousin marriage among 12,448 grandchildren of 891 proband women, using family registers, koseki, at a public office in Nagano Prefecture. The number of married opposite-sex first cousins for each individual had been as many as 10-12 for grandchildren of proband women born during the years $1840-1889$, and began to decrease only recently, whereas the rate of first-cousin marriage has steadily decreased from $5-6 \%$ to $0 \%$ in accord with the trend in the whole country. Thus, the reduction of family size has not played a major role in the recent decrease in consanguinity rate, but may promote it in the new future.
\end{abstract}

\section{INTRODUCTION}

The high frequency of consanguineous marriage in Japan is a matter of common knowledge. Some investigators estimated the frequency of first-cousin marriage in the whole country to be $5-6 \%$ or higher (Neel et al., 1949; Freire-Maia, 1957; Schull and Neel, 1965; Komai, 1972). However, a nation-wide survey carried out in 1972 by the Institute of Population Problem, Ministry of Health and Welfare, Japan (Institute of Population Problem, 1973; Imaizumi et al., 1975), revealed that the frequency of consanguinity in Japan had rapidly decreased from $16.25 \%$ among couples married on June 1, 1947 or earlier to $3.30 \%$ among those married during the

1 This study was supported by Scientific Research Grants from the Ministry of Education, Science and Culture, of Japan No. 0413 in 1964 and No. 0412 in 1965, a Grant from the Toyo Rayon Foundation for the Promotion of Science and Technology 1965-1967, and a Grant from the Ministry of Health and Welfare for Research on Handicapped Children in 1974-1976.

A part of the present study was reported at the 39th Annual Meeting (1967) of the Genetic Society of Japan and at the 13th (1968) and 21st (1976) Annual Meetings of the Japan Society of Human Genetics by Tanaka and Yokoo (1967 and 1968) and Tanaka (1976).

Received April 30, 1977 
period from June 2, 1967 to June 1, 1972, and the frequency of first-cousin marriage from $7.19 \%$ to $0.89 \%$ in the same period excluding those in whom information on consanguinity was not available.

This tendency was foreseen by Matsunaga in 1966, who pointed out that a decrease in potentially marriageable relatives due to an observed rapid reduction in the mean and the variance of sibship size, on one hand, and a modern trend toward the breakdown of isolates, on the other hand, should in the near future result in a significant reduction in the frequency of consanguineous marriages in Japan.

The present communication was undertaken to clarify which factor of the two suggested by Matsunaga has played a more important role in the recent reduction in the consanguinity rate.

\section{MATERIALS AND METHODS}

At a public office in a rural community in the central district of Nagano Prefecture, all married women born during the years 1800-1909 were selected as probands from family registers, koseki, kept in the office. From the koseki of the probands and their progeny, the following data were obtained:

1) Dates of birth, marriage and death of each proband,

2) Name, registered locality and dates of birth and death of the husband of the proband,

3) Similar information on all children and grandchildren for each proband.

Illegitimate unions were not included in the data, since the koseki lacks such records.

Data up to August 1975 for 891 probands, 5,228 children and 12,448 grandchildren were used for the study. The probands were classified into 11 ten-year groups by the year of birth (Table 1). In groups (1)-(8) all surving grandchildren had reached the reproductive age and about $90 \%$ of them had legally married. Some grandchildren in group (9) and increasing proportions in groups (10) and (11) were under reproductive age and some sibships were not completed in group (11).

For each proband and her descendants a three-generation pedigree was constructed, as exemplified in Fig. 1, and the number of grandchildren married to first cousins and number of married opposite-sex first cousins for each married grandchild were counted. Means of these totals were calculated for each 10-year group. In groups (9)-(11), the mean number of opposite-sex first cousins per individual was also calculated including unmarried individuals, since a substantial portion of the grandchildren were too young to be married, but excluding those deceased unmarried.

The mean number of opposite-sex first cousins for each grandchild was calculated by a simple method devised by the present authors, details of which were reported elsewhere (Tanaka et al., 1977).

Till now, first cousins on only one parental side, paternal or maternal, of each 
Table 1. Materials.

\begin{tabular}{|c|c|c|c|c|c|c|}
\hline \multicolumn{3}{|c|}{ Propositi } & \multicolumn{2}{|c|}{$\begin{array}{l}\text { Live born } \\
\text { grandchildren }\end{array}$} & \multicolumn{2}{|c|}{$\begin{array}{l}\text { Excluded deceased } \\
\text { unmarried }\end{array}$} \\
\hline Group & Date of birth & No. & Total & Married $(\%)$ & Total & ( $\%$ Married $)$ \\
\hline (1) & $1800-09$ & 6 & 39 & $31(79.5)$ & & \\
\hline (2) & $1810-19$ & 9 & 88 & $68(77.3)$ & & \\
\hline (3) & $1820^{-29}$ & 39 & 484 & $362(74.8)$ & & \\
\hline (4) & $1830-39$ & 60 & 848 & $597(70.4)$ & & \\
\hline (5) & 1840 -'49 & 92 & 1,513 & $1,028(67.9)$ & & \\
\hline (6) & $1850-59$ & 92 & 1,869 & $1,224(65.5)$ & & \\
\hline (7) & $1860-' 69$ & 108 & 1,891 & $1,274(67.4)$ & 1,407 & $(90.5)$ \\
\hline (8) & $1870^{-9} 79$ & 156 & 2,484 & $1,807(72.7)$ & 2,026 & $(89.2)$ \\
\hline (9) & $1880-89$ & 149 & 1,776 & $1,087(61.2)$ & 1,579 & $(68.8)$ \\
\hline$(10)$ & $1890-99$ & 151 & 1,291 & $356(27.6)$ & 1,209 & $(29.4)$ \\
\hline (11) & $1900-09$ & 29 & 165 & 13 (7.9) & 154 & $(8.4)$ \\
\hline Tota] & & 891 & 12,448 & 7,849 & & \\
\hline
\end{tabular}
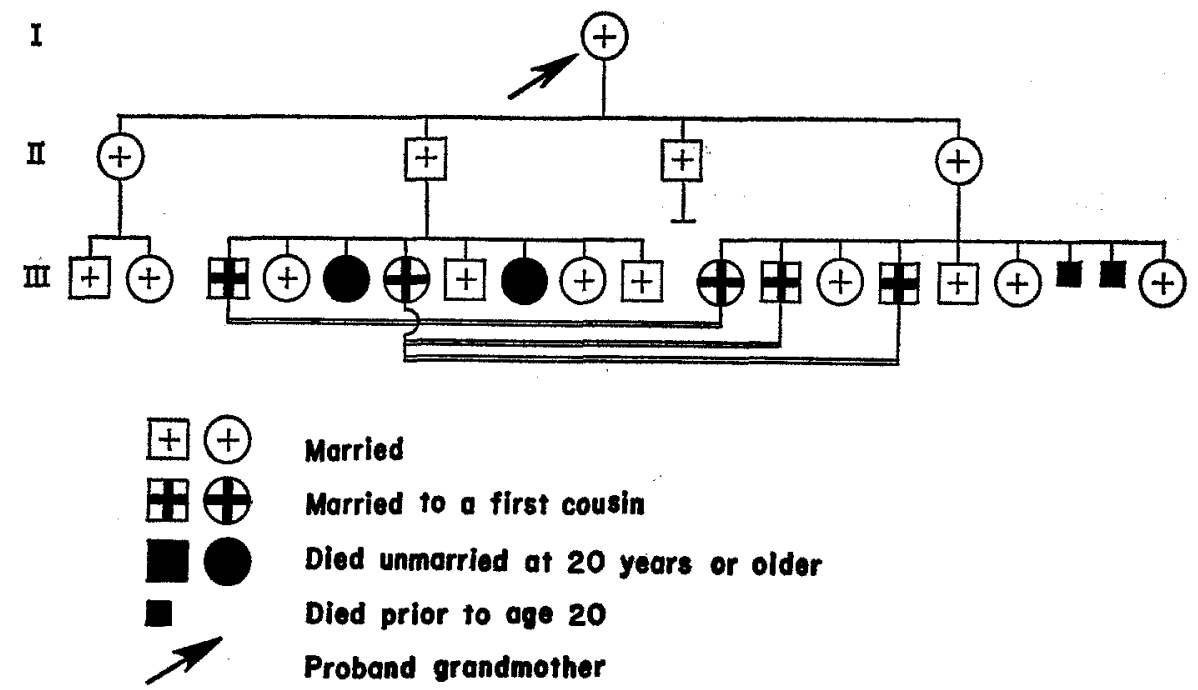

Fig. 1. A proband grandmother, her children and grandchildren (Pedigree No. 10-003). Of 19 liveborn grandchildren, 2 died prior to age 20, 2 died at 20 years or older, and 15 married, of whom 5 married to first cousins.

grandchild have been considered. For the following analyses, doubles of the figures obtained above will be used as the total number of first cousins on both parental sides, assuming that the number of opposite-sex first cousins is equal on both parental sides. 


\section{RESULTS}

As summarized in Table 2, the mean number of married opposite-sex first cousins for each married grandchild increased from group (1) up to group (5). The number was maintained a level as high as 10.1-12.7 through the four 10-year groups (5)-(8), and subsequently decreased. A part of the decrease in groups (9) and (10) is ascribed to the fact that some individuals has not reached the reproductive age. Thus, the figures for groups (9) and (10) are apparently underestimates. The mean number of opposite-sex first cousins for each individual calculated, including unmarried but excluding deceased unmarried individuals, is 10.07 and 6.70 for groups (9) and (10), respectively, which may be upper limits of the mean numbers of married oppositesex first cousins for each married individuals. Such numbers for group (11) are not reliable, since most individuals had not married and some sibships were not completed.

On the other hand, the frequency of first-cousin marriage has steadily decreased from 5-6\% among grandchildren of the probands born during the years of 1800-1849, i.e. groups (1)-(5), to $0.9 \%$ among those of group (8), in which the probands were born during 1870-1879. In the last three groups, (9)-(11), whose proband grandmothers were born during 1880-1909, none of 1,456 married grandchildren was wedded to a first cousin. The upper limit of the observed rate, 0 in 1,456 , corresponds to $0.26 \%$ at the $95 \%$ confidence level.

\section{DISCUSSION}

The basic presumption of the present analysis is that, if the recent reduction in the frequency of first-cousin marriage was in parallel with the reduction in the mean

Table 2. Chronological changes in the mean number of married opposite-sex first cousins for each married individual and in the frequency of those married to first cousins.

\begin{tabular}{|c|c|c|c|c|c|c|}
\hline \multicolumn{2}{|c|}{ Propositi } & \multirow{2}{*}{$\begin{array}{l}\text { Mean number of married } \\
\text { opposite-sex 1st cousins } \\
\text { per married individual }\end{array}$} & \multicolumn{4}{|c|}{ Married grandchildren } \\
\hline Group & $\begin{array}{l}\text { Date of } \\
\text { birth }\end{array}$ & & Total & $\begin{array}{c}\text { Marrie } \\
\text { No. }\end{array}$ & $\begin{array}{l}\text { to } 1 \\
\%\end{array}$ & cousin \\
\hline (1) & $1800-99$ & 1.81 & 31 & 3 & 9.68 & \\
\hline (2) & $1810-19$ & 6.12 & 68 & 2 & 2.94 & \\
\hline (3) & $1820-29$ & 8.27 & 362 & 33 & 9.12 & 5.20 \\
\hline (4) & $1830-' 39$ & 8.13 & 597 & 17 & 2.85 & \\
\hline (5) & $1840-{ }^{\prime} 49$ & 10.12 & 1,028 & 62 & 6.03 & \\
\hline (6) & $1850-59$ & 12.67 & 1,224 & 55 & 4.49 & \\
\hline (7) & $1860-69$ & $10.78\left(12.16^{*}\right)$ & 1,274 & 30 & 2.35 & \\
\hline (8) & $1870-79$ & $11.04\left(12.23^{*}\right)$ & 1,807 & 16 & 0.89 & \\
\hline (9) & $1880-' 89$ & $7.20\left(10.07^{*}\right)$ & 1,087 & 0 & $\mathbf{0}$ & \\
\hline (10) & 1890-'99 & $2.33\left(6.70^{*}\right)$ & 356 & 0 & 0 & \\
\hline (11) & $1900-09$ & $0.92 \quad\left(4.42^{*}\right)$ & 13 & 0 & 0 & \\
\hline Total & & & 7,847 & 218 & & \\
\hline
\end{tabular}

* Mean number of opposite-sex first cousins per individual calculated by including unmarried but excluding deceased unmarried individuals. 
number of opposite-sex first cousins for each individual, the latter may have played an important role in the former. However, the present observations are not accord with this assumption. The mean number of married opposite-sex first cousins for each married individual was almost constant, 10.1-12.7, among grandchildren in groups (5)-(8) whose proband grandmothers were born during the years 1840-1879, and nearly 10 even in group (9) whose grandmothers were born in $1880-1889$.

On the other hand, first-cousin marriages have decreased from $6 \%$ in group (5) to $0 \%(0$ in 1,456$)$ in groups $(9)-(11)$, quite similarly to the trend for the entire country (Imaizumi et al., 1975).

The results obtained may not be unexpected, since the mean number of first cousins for each individual is a function of the sibship sizes in parent and offspring generations and the rapid decrease in sibship size and its variance was not found in children of mothers who were born in 1910 or earlier (Bureau of Statistics, 1962). Thus, the recent drastic decrease in consanguineous marriages in Japan may not be ascribable to the decrease in the mean number of potentially marriageable relatives, but mainly to following factors:

1) Modern transport facilities have been increasingly breaking down the geographical barriers among populations that had been isolated in the past.

2) Industrialization has promoted emigration, especially of young unmarried people, from all over the country to large cities, where the youngesters have the chance to become aquainted with each other. The remarkable increase of male and female students of colleges or universities has a similar effect. It must be noted that a majority of the children and grandchildren of the probands under study also had emigrated from the home village to various districts of the country. 3) All textbooks on hygiene for junior high school children include a description of the adverse effects of consanguineous marriage on offspring, which have become common knowledge for those under 40 years of age educated using these textbooks.

4) The newly enacted constitution and the awakened idea of personal rights after World War II have given rise to a trend toward establishing a new family system including the mode of mate selection instead of the traditional ones which had maintained the high consanguinity rate (Schull and Neel, 1965; Schull et al., 1970; Komai, 1972).

Such social trends have not yet ended. The present study indicates that the decrease in family size has played less important role in the decrease of consanguineous marriages in the past, but also that it began to reduce the number of potentially marriageable first cousins for each individual as shown in group (10). Thus, the consanguinity rate in Japan will undoubtedly continue to decrease in the future where the reduction in family size may play a more important role.

Acknowledgments The authors are grateful to Mr. Masuho Chino, Dr. Akio Nozawa, and Tatsuno Public Office and its Kawashima Branch, Nagano Prefecture for their cooperation in the koseki study. 
They are greatly indebted to Misses Sadako Takahashi, Fujiko Oi and Fumiko Higashi for their accomplishment of koseki study and to Miss Junko Yokoo, Miss Masako Tanimura, Mrs. Miyoko Fujisawa and Mrs. Yumiko Karashima for their contribution to the analyses of the data and preparation of the manuscripts.

\section{REFERENCES}

Bureau of Statistics, Office of the Prime Minister. 1962. 1960 Population Census of Japan, Vol. 2: 372-373.

Freire-Maia, N.'1957. Inbreeding levels in different countries, Eugen. Quart. 4: 127-138.

Imaizumi, Y., Shinozaki, N. and Aoki, H. 1975. Inbreeding in Japan:Results of a nation-wide study. Jap. J. Human Genet. 20 (2): 91-107.

Institute of Population Problem. 1973. The Sixth Fertility Survey, Vol. 1 (in Japanese).

Komai, T. 1972. Genetic studies on inbreeding in some Japanese populations. I. Introductory remarks. Jap. J. Human Genet. 17: (2): 87-113.

Matsunaga, E. 1966. Possible genetic consequences of family planning. J. Am. Med. Ass. 198: $533-540$.

Neel, J.Y., Kodani, M., Brewer, R. and Anderson, R.C. 1949. The incidence of consanguineous matings in Japan. Am. J. Human Genet. 1: 156-178.

Schull, W.J., Furusho, T., Yamamoto, M., Nagano, H. and Komatsu, I. 1970. The effect of parental consanguinity and inbreeding in Hirado, Japan. Humangenetik 9: 294-315.

Schull, W.J. and Neel, J.V. 1965. The Effects of Inbreeding on Japanese Children. Harper \& Row, New York.

Tanaka, K., Hayase, R. and Tanimura, M. 1977. Reliability of methods to estimate the number of potentially: marriageable first cousins for an individual, using the mean and variance of sibship sizes. Jap. J. Human Genet. 21 : 239-245.

Tanaka, K. and Yokoo, J. 1967. Possible effects of recent decrease of family size and early deaths on consanguinity rate (Abstract in Japanese). Jap. J. Genet. 42: 441-442.

Tanaka, K. and Yokoo, J. 1968. Recent decrease of marriageable relatives due to decrease of family size (Abstract in Japanese). Jap. J. Human Genet. 13: 133-134. 